\title{
STRATEGI PENGEMBANGAN PT XYZ DALAM AGRIBISNIS TEH HIJAU
}

\author{
Harris Darmawan, Arief Daryanto \& Sukardi \\ Program Studi Manajemen dan Bisnis , Institut Pertanian Bogor, \\ Email: darmawan.harris@yahoo.com \\ Program Pascasarjana Manajemen dan Bisnis, Institut Pertanian Bogor, \\ Email: adaryant@mma.ipb.ac.iddansukardi@ipb.ac.id
}

\begin{abstract}
The growth of tea demand in Indonesia increased, while the national production was not sufficient. Therefore, import is increasing since Asean Free Trade Agreement (AFTA) enforced with 0\% tariff import. The cheapness of imported tea causing domestic producers must increase their competitiveness, including XYZ Company as the biggest green tea producers in Indonesia. The objectives of this study are to: (1) to evaluate the internal and external environmental condition that affect value chain development of XYZ Co.; (2) to formulate alternative strategy for improve production efficiency and value chain effectiveness of XYZ Co.; (3) to determine priority strategy which can be implemented by XYZ Co., for value chain of tea development. The method of the study used was by using observation, in depth interviews and questionnaires to analyze company's value chain, internal and external industry analysis, SWOT analysis, AHP-SWOT for priority strategic and implication managerial. The result of the study showed that the priority strategy were as follow: (1) enhancement capacity production of green tea; (2) build strategically partnerships; (3) production development; (4) product and marketing development; (5) enhancement operational standard; (6) enhancement publication of business.
\end{abstract}

Keywords: AHP-SWOT, Green Tea Agribusiness, Strategic Development, Value Chain Analysis

\begin{abstract}
Abstrak: Pertumbuhan permintaan teh di Indonesia terus meningkat, sedangkan produksi nasional tidak mencukupi. Oleh karena itu, impor terus meningkat sejak Asean Free Trade Agreement (AFTA) diberlakukan dengan 0\% tarif impor. Murahnya teh impor menyebabkan produsen dalam negeri harus meningkatkan daya saing mereka, termasuk PT. XYZ sebagai salah satu produsen teh hijau terbesar di Indonesia. Penelitian ini bertujuan untuk: (1) mengevaluasi faktor lingkungan internal dan eksternal yang berpengaruh terhadap pengembangan rantai nilai PT XYZ; (2) merumuskan alternatif strategi yang dapat meningkatkan efisiensi produksi serta efektifitas rantai nilai PT XYZ; (3) menentukan prioritas strategi yang dapat diimplementasikan oleh PT XYZ untuk pengembangan rantai nilai teh. Metode penelitian yang digunakan adalah menggunakan observasi, wawancara dan kuesioner untuk menganalisis rantai nilai perusahaan, analisis industry internal dan eksternal, analisis SWOT, analisis AHP-SWOT untuk prioritas strategi dan implikasi manajerial. Hasil penelitian menunjukkan prioritas strategi adalah sebagai berikut: (1) peningkatan kapasitas produksi teh hijau; (2) pengembangan kerjasama perusahaan; (3) pengembangan produksi; (4) pengembangan produk dan pemasaran; (5) peningkatan standar operasional; (6) peningkatan publikasi usaha.
\end{abstract}


Kata Kunci: AHP-SWOT, Agribisnis Teh Hijau, Strategi Pengembangan, Analisis Rantai Nilai

JEL: Q130

\section{PENDAHULUAN}

Pertumbuhan sektor agribisnis di Indonesia tidak terlepas dari peran aktif rakyat, swasta serta pemerintah sebagai aktor utama penggerak agroindustri. Pemerintah berperan melalui Badan Usaha Milik Negara (BUMN), salah satu diantaranya adalah PT XYZ. PT XYZ merupakan salah satu anak perusahaan dari suatu induk perusahaan BUMN yang bergerak di sektor agribisnis. Salah satu perhatian utama holding saat ini adalah pembenahan kinerja PT XYZ. Menurut PT XYZ Annual Report 2011, perusahaan terus mengalami fluktuasi penjualan dari tahun 2007 hingga 2011. Penjualan tahun 2008 hingga 2010 terus mengalami tren peningkatan, akan tetapi penjualan di tahun 2011 mengalami penurunan cukup signifikan. Besaran penurunan penjualan tidak diimbangi dengan besaran penurunan Harga Pokok Penjualan (HPP), hal tersebut membuat kondisi keuangan perusahaan defisit. HPP yang tinggi menandakan perusahaan memiliki tingkat efisiensi yang masih tergolong rendah dalam menjalankan produksinya. Menurut laporan pertanggungjawaban manajemen dalam PT XYZ Annual Report 2011, tahun 2011 merupakan tahun yang cukup berat untuk bisnis dibidang perkebunan teh Indonesia. Kondisi ini disebabkan iklim cuaca yang tidak mendukung bagi perkebunan, persaingan banyaknya teh impor yang dilakukan oleh industri hilir teh dan juga industri minuman dari teh (ready to drink) turut menambah derasnya arus persaingan industri teh PT XYZ.

Alasan pihak manajemen tentang persaingan teh nasional diperkuat dari data pada Tabel 1. Tingkat persentase impor terhadap permintaan teh dalam negeri mengalami peningkatan besar pada tahun 2011. Hal ini seiring berkembangnya industri hilir teh di Indonesia, baik dalam bentuk teh minuman siap saji, teh celup, kosmetik, makanan, serta farmasi yang tidak diikuti dengan bertambahnya jumlah produksi teh nasional. Jumlah pertambahan tingkat konsumsi teh dalam negeri ini justru dipenuhi dari teh impor. Bea masuk teh impor sebesar 0\% sebagai konsekuensi Indonesia terjalin dalam kerjasama ASEAN Free Trade Agreement (AFTA) semakin memperbesar arus masuk teh impor. Fakta tersebut dapat menjadi peluang sekaligus ancaman bagi produsen teh dalam negeri, dikatakan peluang karena terus meningkatnya jumlah konsumsi teh dalam negeri setiap tahun, sedangkan dikatakan sebagai ancaman karena murahnya teh impor yang masuk ke Indonesia.

Alasan iklim cuaca merupakan faktor alam yang tidak dapat dikendalikan oleh manusia, tetapi persaingan industri adalah hal yang berbeda. Mengingat situasi persaingan bisnis yang semakin ketat dikarenakan dampak globalisasi diberlakukannya era perdagangan bebas telah menggeser paradigma bisnis dari Comparative Advantage menjadi Competitive Advantage, yang memaksa kegiatan bisnis/perusahaan memilih strategi yang mampu membawa perusahaan berada dalam posisi strategis serta mampu beradaptasi dengan lingkungan yang terus berubah (Widiarsono 2010). PT XYZ membutuhkan suatu strategi pengembangan yang berfokus pada peningkatan efisiensi produksi serta efektifitas rantai nilai agar perusahaan mampu meningkatkan daya saingnya. Dari penjelasan latar belakang dan permasalahan yang telah dikemukakan, maka tujuan dari penelitian ini adalah: (1) Mengevaluasi faktor lingkungan internal dan eksternal yang berpengaruh terhadap pengelolaan rantai nilai PT XYZ; (2) Merumuskan 
alternatif strategi yang dapat meningkatkan efisiensi produksi serta efektifitas rantai nilai PT XYZ.; (3) Menentukan prioritas strategi yang dapat diimplementasikan oleh PT XYZ dalam pengelolaan rantai nilai teh.

Tabel 1. Jumlah Permintaan dan Persentase Impor Teh Indonesia 2007-2011 (Ton)

\begin{tabular}{llllll}
\hline \multicolumn{1}{c}{ Keterangan } & \multicolumn{5}{c}{ Tahun } \\
\cline { 2 - 6 } & \multicolumn{1}{c}{2007} & \multicolumn{1}{c}{2008} & 2009 & \multicolumn{1}{c}{2010} & \multicolumn{1}{c}{2011} \\
\hline Produksi & 150.623 & 153.971 & 156.901 & 156.604 & 140.944 \\
Ekspor & 83.659 & 96.210 & 92.304 & 87.101 & 75.450 \\
Retensi & 66.964 & 57.761 & 64.597 & 69.503 & 65.494 \\
Impor & 8.695 & 6.625 & 7.169 & 10.870 & 19.812 \\
Permintaan Teh Dalam Negeri & 75.659 & 64.386 & 71.766 & 80.373 & 85.306 \\
$\begin{array}{l}\text { Persentase impor terhadap } \\
\text { permintaan dalam negeri }\end{array}$ & 11,49 & 10,29 & 9,99 & 13,52 & 23,22 \\
\hline
\end{tabular}

Sumber: diolah dari BPS (2011)

\section{METODE}

Penelitian ini dilaksanakan pada bulan Januari 2013 hingga Juni 2013 dengan mengambil lokasi di kebun dan pabrik teh milik PT XYZ. Metode penelitian yang digunakan dalam penelitian ini adalah analisis deskriptif bertujuan untuk mendapatkan gambaran perusahaan secara mendalam tentang hal-hal yang berkaitan di dalam aktifitas rantai nilai pengolahan teh hijau serta seluruh pemangku kepentingan yang terlibat di dalam rantai nilai tersebut. Penentuan responden menggunakan teknik purposive sampling yang didasarkan pada pertimbangan keahlian, pengetahuan dan pengalaman responden. Adapun responden internal yang dilibatkan antara lain Site Manager, Manajer Operasional, Manajer Keuangan, Manajer SDM, Kepala Tanaman dan Kepala Komersil PT XYZ. Sedangkan responden eksternal antara lain Kepala Divisi Bisnis PPTK Gambung, Riset dan beberapa klien perusahaan yang berperan sebagai trader. Jenis data yang digunakan dalam penelitian ini adalah data primer dan data sekunder. Alat analisis dalam penelitian ini adalah analisis rantai nilai, analisis faktor internal dan eksternal, analisis SWOT dan analisis AHP-SWOT.

\section{HASIL DAN PEMBAHASAN}

Analisis Rantai Nilai. Menurut Pietrobelli dan Rabelloti (2005), rantai nilai mencakup semua kegiatan yang diperlukan untuk membuat produk, mulai dari konsepsi hingga produk tersebut dipasarkan. Kegiatan tersebut meliputi pengembangan produk, tahap produksi yang berbeda-beda antar produk, ekstraksi bahan mentah, bahan setengah jadi, bahan jadi, produksi komponen dan perakitan, distribusi, pemasaran, bahkan hingga daur ulang produk. Tujuan dilakukannya pemetaan rantai nilai adalah untuk mengetahui pola peranan dan aktifitas-aktifitas penting (core processes) yang dilakukan oleh setiap aktor/pelaku bisnis di dalam rantai nilai teh hijau di PT XYZ. Aktifitas penting tersebut pada dasarnya adalah segala kegiatan penciptaan dan peningkatan nilai teh dari awalnya hanya sekedar daun teh pucuk basah hingga akhirnya menjadi teh jadi siap dikonsumsi. Kegiatan ini juga merupakan suatu upaya peningkatan nilai dan keunggulan kompetitif 
bagi perusahaan atau pelaku bisnis. Hasil pemetaan rantai nilai teh hijau PT XYZ disajikan pada Gambar 1.

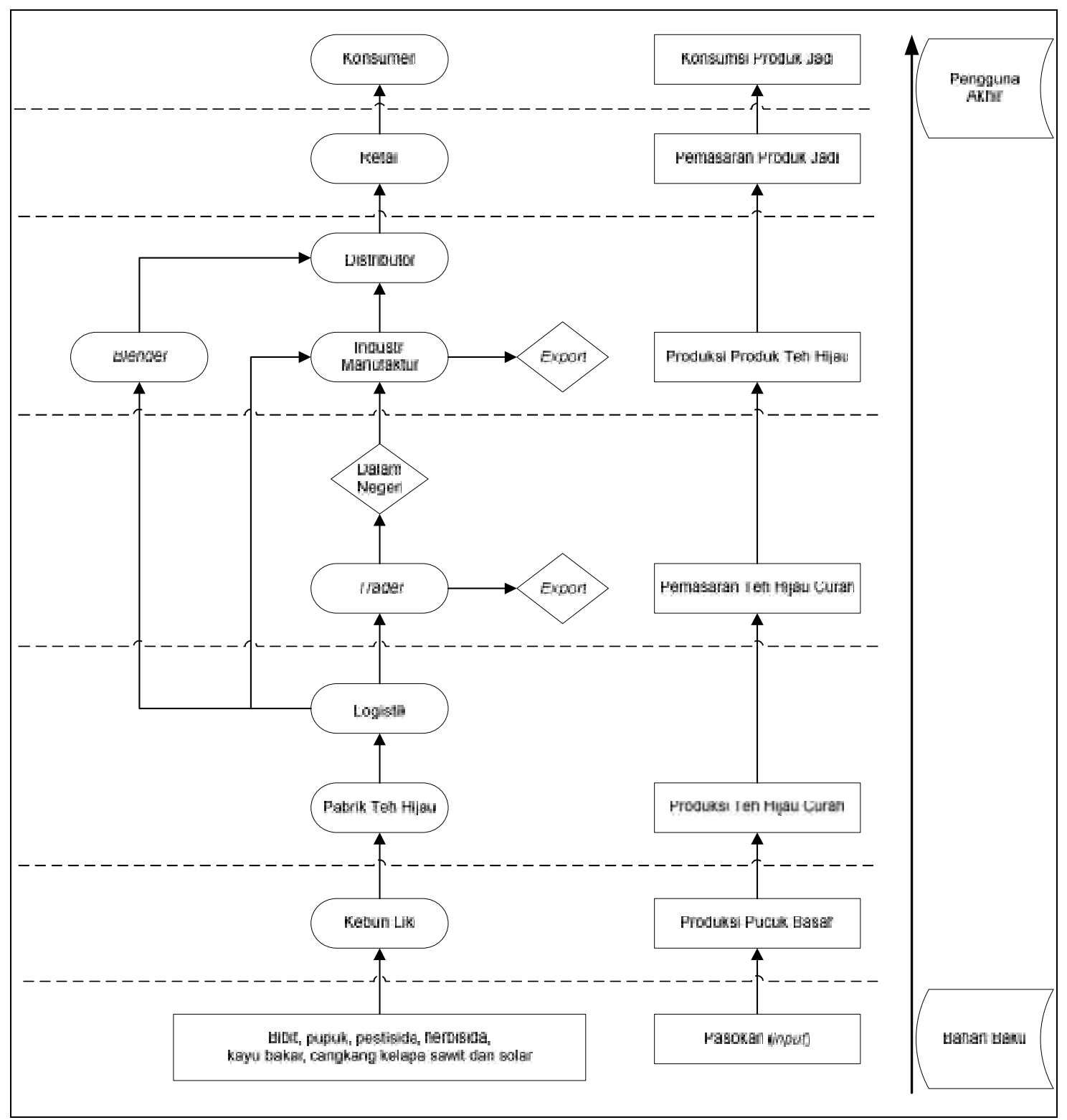

Gambar 1. Peta Rantai Nilai Teh Hijau PT XYZ

Analisis Lingkungan Internal. Faktor lingkungan internal perusahaan adalah seluruh aspek yang dimiliki perusahaan guna mencapai tujuan suatu perusahaan. Menurut David (2007), analisis lingkungan internal meliputi identifikasi dan evaluasi kekuatan dan kelemahan perusahaan pada area fungsional bisnis, termasuk manajemen, pemasaran, keuangan/akuntansi, produksi/operasi, penelitian dan pengembangan, dan sistem informasi manajemen. Pada dasarnya setiap organisasi memiliki kekuatan dan kelemahan. Kelemahan haruslah senantiasa diperbaiki secara terus menerus agar dapat diubah menjadi salah satu kekuatan organisasi dan bahkan bila memungkinkan dapat ditingkatkan lagi menjadi kompetensi pembeda (distinctive competencies) karena bila perusahaan memiliki kompetensi pembeda dapat membuat suatu organisasi menjadi semakin kuat. Identifikasi 
aspek kekuatan dan kelemahan internal perusahaan didapatkan melalui analisis rantai nilai lebih mendalam, dimana aspek lingkungan internal ini dapat menentukan kinerja perusahaan sesuai kemampuan yang dimiliki. Adapun hasil identifikasi faktor internal PT XYZ dapat dilihat pada Tabel 2.

Tabel 2. Identifikasi Faktor Internal PT XYZ

\begin{tabular}{|c|c|c|}
\hline Aspek & Faktor & $\begin{array}{l}\text { Kekuatan/ } \\
\text { Kelemahan }\end{array}$ \\
\hline Keuangan & $\begin{array}{l}\text { Kondisi finansial yang kuat karena selalu didukung oleh pihak } \\
\text { induk perusahaan. }\end{array}$ & Kekuatan \\
\hline \multirow[t]{7}{*}{ Produksi } & $\begin{array}{l}\text { PT XYZ sebagai produsen teh hijau terbesar di Indonesia } \\
\text { dengan kapasitas produksi mencapai } 48 \text { ton pucuk basah per } \\
\text { hari. }\end{array}$ & Kekuatan \\
\hline & $\begin{array}{l}\text { Memiliki aset areal kebun } \mathrm{HGU} \text { seluas } 2.025,30 \text { ha dengan } \\
80 \% \text { lahannya memiliki topografi relatif rata serta ketinggian } \\
\text { areal dan curah hujan relatif tinggi. }\end{array}$ & Kekuatan \\
\hline & $\begin{array}{l}\text { Tanaman masih tergolong produktif, berumur antara } 10-27 \\
\text { tahun dan memiliki kadar tanin teh tergolong tinggi, yaitu } \\
\text { sekitar } 18 \% \text {. }\end{array}$ & Kekuatan \\
\hline & $\begin{array}{l}\text { Tingginya tingkat ketergantungan terhadap solar sebagai energi } \\
\text { alternatif ketika PLN padam, sehingga sangat membebani } \\
\text { biaya produksi. }\end{array}$ & Kelemahan \\
\hline & $\begin{array}{l}\text { Pemakaian kayu bakar sebagai energi alternatif terkadang } \\
\text { menimbulkan kontaminasi aroma asap pada seduhan teh jadi, } \\
\text { dan kesulitan mengatur suhu yang diinginkan. }\end{array}$ & Kelemahan \\
\hline & $\begin{array}{l}\text { Lamanya proses Pengeringan II pada BT memakan waktu 10- } \\
14 \text { jam sehingga terkadang menyebabkan antrian teh. }\end{array}$ & Kelemahan \\
\hline & Antrian teh pucuk basah pada WT masih cukup banyak. & nahan \\
\hline Pemasaran & $\begin{array}{l}\text { Akses mudah untuk mengikuti pameran teh sebagai delegasi } \\
\text { perusahaan negara. }\end{array}$ & Kekuatan \\
\hline $\mathrm{R} \& \mathrm{D}$ & $\begin{array}{l}\text { Pemberdayaan Riset dan Pengembangan perusahaan masih } \\
\text { belum optimal. }\end{array}$ & Kelemahan \\
\hline
\end{tabular}

Analisis Lingkungan Eksternal. Lingkungan eksternal adalah suatu kekuatan yang letaknya berada di luar perusahaan, dimana dalam hal ini perusahaan tidak mempunyai pengaruh sama sekali terhadapnya (uncontrollable) sehingga perubahan yang terjadi pada lingkungan ini akan mempengaruhi kinerja seluruh perusahaan yang berkecimpung dalam industri tersebut (Umar 2003). Hasil identifikasi faktor eksternal dapat dilihat pada Tabel 3.

Analisis Alternatif Strategi. Menurut Moser (2006), satu dari rangkaian alat analisis yang efektif untuk merancang strategi adalah dengan menggunakan analisis SWOT. Analisis SWOT dapat membantu perusahaan untuk menyesuaikan posisi relatifnya terhadap para pesaingnya. Analisis SWOT memudahkan perusahaan dalam 
mengidentifikasi semua tindakan/kegiatan perusahaan. Adam (2005) menambahkan bahwa analisis SWOT tidak cocok digunakan oleh para eksekutif untuk menyelesaikan permasalahan setiap hari, tetapi analisis SWOT sebaiknya digunakan setahun sekali untuk membantu menyelesaikan permasalahan perusahaan.

Tabel 3. Identifikasi Faktor Eksternal PT XYZ

\begin{tabular}{lll}
\hline \multicolumn{1}{c}{ Aspek } & \multicolumn{1}{c}{ Faktor } & \multicolumn{1}{c}{\begin{tabular}{c}
\multicolumn{1}{c}{ Peluang/ } \\
Ancaman
\end{tabular}} \\
\hline $\begin{array}{l}\text { Politik, } \\
\text { Pemerintah } \\
\text { dan Hukum }\end{array}$ & $\begin{array}{l}\text { Kesepakatan AFTA yang mengakibatkan Indonesia dibanjiri } \\
\text { teh impor. }\end{array}$ & Ancaman \\
& $\begin{array}{l}\text { Kebutuhan teh bagi industri manufaktur RTD tiap tahun terus } \\
\text { meningkat. }\end{array}$ & Peluang \\
& $\begin{array}{l}\text { Program rehabilitasi area perkebunan teh rakyat GPATN. } \\
\text { Penerapan SNI wajib untuk teh yang akan diberlakukan oleh } \\
\text { pemerintah, baik untuk teh impor maupun teh di pasar } \\
\text { domestik. }\end{array}$ & Ancaman \\
\hline Ekonomi & $\begin{array}{l}\text { Indonesia merupakan pasar yang sangat berpotensial dengan } \\
\text { jumlah penduduk ke-4 terbesar di dunia. }\end{array}$ & Ancaman \\
& $\begin{array}{l}\text { Penduduk kelas menengah di Indonesia setiap tahun terus } \\
\text { meningkat. }\end{array}$ & Peluang \\
\hline $\begin{array}{l}\text { Sosial dan } \\
\text { Budaya }\end{array}$ & $\begin{array}{l}\text { Meningkatnya minat masyarakat dunia atas minuman bebas } \\
\text { kandungan bahan kimia (organik). }\end{array}$ & Peluang \\
& $\begin{array}{l}\text { Masih rendahnya tingkat apresiasi masyarakat dalam negeri } \\
\text { terhadap teh berkualitas. }\end{array}$ & Ancaman \\
\hline Teknologi & Berkembangnya teknologi ekstraksi teh hijau. & Peluang \\
\hline
\end{tabular}

Penggunaan alat analisis ini sebaiknya terlebih dahulu memahami dan mengetahui proses bisnis perusahaan yang sedang dijalani, tujuannya untuk menemukan kekuatan, kelemahan, peluang dan ancaman yang ada dan membuatnya menjadi sebuah action plan.

David (2007) menyatakan bahwa Matriks TOWS dapat digunakan untuk merumuskan strategi masa depan perusahaan. Matriks TOWS dapat menghasilkan empat kemungkinan strategi yang dihasilkan sebagai berikut: (1) Strategi SO (StrenghtsOpportunities), yaitu strategi yang menggunakan kekuatan yang dimiliki untuk mengambil peluang; (2) Strategi ST (Strengths-Threats) merupakan strategi yang menggunakan kekuatan untuk menghindari dan mengatasi ancaman; (3) Strategi WO (WeaknessesOpportunities) sebagai strategi yang menggunakan peluang yang dimiliki untuk mengatasi kelemahan; (4) Strategi WT (Weaknesses-Threats) adalah strategi untuk meminimumkan kelemahan dan menghindari ancaman.

Berdasarkan hasil analisis rantai nilai serta analisis lingkungan internal dan lingkungan eksternal, maka diperoleh dari setiap analisis tersebut suatu strategi yang dapat dilakukan oleh perusahaan melalui matriks TOWS yang ditampilkan pada Gambar 2. 


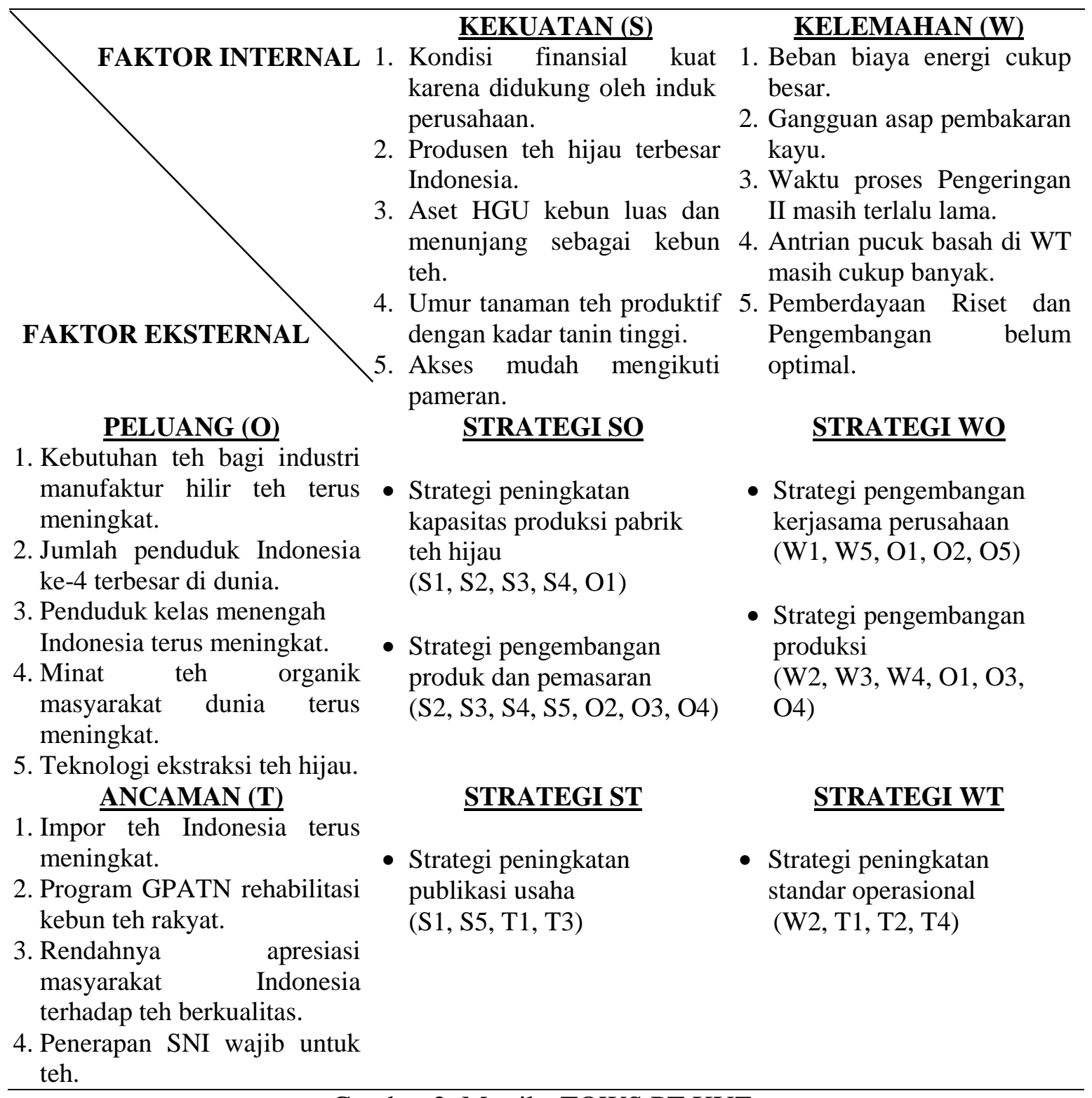

\section{Gambar 2. Matriks TOWS PT XYZ}

Analisis Alternatif Strategi Peningkatan Efisiensi. Berikut beberapa analisis alternatif strategi yang direkomendasikan sebagai peningkatan efisiensi produksi teh hijau PT XYZ, yaitu:

1. Strategi Pengembangan Kerjasama Perusahaan: Kendala utama pabrik saat ini adalah keterbatasannya pasokan listrik oleh PLN, sehingga pada saat beban puncak PLN memutuskan aliran listrik ke pabrik sehingga pabrik menggunakan alternatif pasokan listrik dari genset. Perusahaan dapat mengupayakan pengadaan Pembangkit Listrik Tenaga Mini Hidro (PLTMH) sebagai sumber listrik pabrik. Potensi air terjun Tansi Ampek mampu menghasilkan listrik sebesar 9,6 MW. Saat ini, terhitung beban HPP genset beroperasi per jam sebesar Rp. 3.400,00 - Rp. 4.000,00/kwh dengan rata-rata waktu operasi selama 5 jam/hari, sedangkan sisanya menggunakan pasokan listrik dari PLN dengan beban HPP PLN per jam sebesar Rp. 720,00 - Rp. 800,00/kwh. Kombinasi 
penggunaan antara PLN dan genset setiap hari membentuk harga HPP listrik pabrik sebesar Rp. 1.200,00. Berdasarkan Peraturan Menteri Energi dan Sumber Daya Mineral (ESDM) Nomor 31 Tahun 2009 Pasal 1 yang mewajibkan PT PLN (Persero) membeli tenaga listrik dari pembangkit tenaga listrik yang menggunakan energi terbarukan skala kecil dan menengah dengan kapasitas sampai dengan $10 \mathrm{MW}$ atau kelebihan tenaga listrik (excess power) dari badan usaha milik negara. Beroperasinya PLTMH akan memenuhi tingkat kebutuhan pasokan listrik Pabrik Pengolahan Teh Hijau PT XYZ sehingga genset tidak perlu beroperasi lagi. Kondisi ideal ini akan menurunkan harga HPP konsumsi listrik pabrik dari Rp. 1.200,00 menjadi Rp. 800,00. Efisiensi HPP listrik sebesar Rp. 400,00 ini akan menurunkan HPP target RKAP produksi pucuk basah pasca pemupukan Maret 2013 sebanyak \pm 60 ton (rendemen teh kering $23,5 \%$ ) dengan perhitungan sebagai berikut:

Efisiensi HPP listrik per bulan adalah:

$$
\begin{aligned}
& =\text { Rp. } 400,00 \times(24 \mathrm{HOK} \times 60.000 \mathrm{~kg} \times 23,5 \%) \times 0,95 \mathrm{kwh} / \mathrm{kg} \\
& \text { t.k. } \\
& =\text { Rp. } 128.592 .000,00
\end{aligned}
$$

Besaran efisiensi HPP teh kering per kilogram adalah:

$$
\begin{aligned}
& =\text { Rp. } 128.592 .000,00: 338.400 \mathrm{~kg} \text { t.k } \\
& =\text { Rp. } 380,00
\end{aligned}
$$

Pengembangan kerjasama dapat ditempuh dalam upaya pembangunan PLTMH dengan menggandeng pihak swasta yang ahli di proyek pembangunan PLTMH serta mengajak kerjasama PT PLN (Persero) terkait dengan Peraturan Menteri ESDM Nomor 31 Tahun 2009.

2. Strategi Peningkatan Kapasitas Produksi Pabrik Teh Hijau. Strategi peningkatan kapasitas produksi sebagai perwujudan prinsip economic of scale, sekaligus langkah pengoptimalan produksi teh hijau karena peningkatan produksi pucuk basah dari kebun pasca pemupukan bulan Maret 2013 yang tercatat pada bulan Mei 2013 sudah menghasilkan produksi pucuk basah sebesar $\pm 60.000 \mathrm{~kg}$ pucuk basah per hari.

Asumsi: mesin beroperasi 24 jam/hari, 24 Hari Orang Kerja (HOK)/bulan

1. Mesin RP (3 unit)

Kapasitas input $/$ unit $=750 \mathrm{~kg} / \mathrm{jam}$

Kapasitas input RP/hari $=54.000 \mathrm{~kg}$

Bottle Neck sebanyak $6.000 \mathrm{~kg}$ pucuk basah tidak terkelola RP

Rekomendasi:

Agar pabrik dapat memenuhi RKAP, maka perlu menambah 1 unit RP, berdasarkan perhitungan:

Kapasitas input RP/hari $=4$ unit x $750 \mathrm{~kg} / \mathrm{jam} \times 24$ jam

$$
=72.000 \mathrm{~kg}
$$

2. Mesin OTR (3 unit)

Kapasitas input $/$ unit $=495 \mathrm{~kg} / \mathrm{jam}$

Kapasitas input OTR/hari $=35.640 \mathrm{~kg}$

Berdasarkan hasil output mesin sebelumnya (Mesin RP), maka terjadi bottle neck sebanyak $24.360 \mathrm{~kg}$ pucuk basah yang tidak terkelola OTR.

Rekomendasi:

Agar pabrik mendekati RKAP, maka perlu menambah 2 unit OTR, 
berdasarkan perhitungan:

Kapasitas input OTR/hari $=5$ unit x $495 \mathrm{~kg} / \mathrm{jam}$ x $24 \mathrm{jam}$

$=59.400 \mathrm{~kg} / \mathrm{hari}$

3. Mesin ECP (6 unit)

Kapasitas input $/ \mathrm{unit}=225 \mathrm{~kg} / \mathrm{jam}$

Kapasitas input ECP/hari $=32.400 \mathrm{~kg}$

- Berdasarkan hasil output mesin sebelumnya (Mesin OTR), maka terjadi bottle neck sebanyak $27.000 \mathrm{~kg}$ pucuk basah yang tidak terkelola ECP.

Rekomendasi:

Agar pabrik dapat mendekati RKAP, maka perlu menambah 5 unit ECP, berdasarkan perhitungan:

Kapasitas input ECP/hari = 11 unit x $225 \mathrm{~kg} / \mathrm{jam} \times 24$ jam

$$
=59.400 \mathrm{~kg} / \mathrm{hari}
$$

4. Mesin Boll Tea (30 unit), terdiri atas:

1. Boll Tea Elektrik

a. $\quad$ BT Taiwan $=5$ unit $x 110 \mathrm{~kg} / 10 \mathrm{jam}=550 \mathrm{~kg} / 10 \mathrm{jam}$.

Kapasitas output dalam 1 bulan (24 HOK) BT Taiwan mampu menghasilkan output sebanyak $=57$ proses $\times 550 \mathrm{~kg} / 10 \mathrm{jam}$

$$
=31.350 \mathrm{~kg} / \mathrm{bulan}
$$

b. BT Standar $=9$ unit $\times 220 \mathrm{~kg} / 12 \mathrm{jam}=1.980 \mathrm{~kg} / 12 \mathrm{jam}$.

Kapasitas output dalam 1 bulan (24 HOK) BT Standar mampu menghasilkan output sebanyak $=48$ proses $\times 1.980 \mathrm{~kg} / 12 \mathrm{jam}$

$$
=95.040 \mathrm{~kg} / \mathrm{bulan}
$$

c. BT Jumbo $=2$ unit $x 380 \mathrm{~kg} / 16 \mathrm{jam}=760 \mathrm{~kg} / 16 \mathrm{jam}$.

Kapasitas output dalam 1 bulan (24 HOK) BT Jumbo mampu menghasilkan output sebanyak $=36$ proses $\times 760 \mathrm{~kg} / 16 \mathrm{jam}$

$$
=27.360 \mathrm{~kg} / \mathrm{bulan}
$$

2. Boll Tea Kayu Bakar

a. BT Standar $=12$ unit x $220 \mathrm{~kg} / 12 \mathrm{jam}=2.640 \mathrm{~kg} / 12 \mathrm{jam}$.

Kapasitas output dalam 1 bulan (24 HOK) BT Standar ini mampu menghasilkan output sebanyak $=48$ proses $\mathrm{x} 2.640 \mathrm{~kg} / 12 \mathrm{jam}$

$$
=126.720 \mathrm{~kg} / \mathrm{bulan}
$$

b. BT Jumbo $=2$ unit $\times 380 \mathrm{~kg} / 12 \mathrm{jam}=760 \mathrm{~kg} / 12 \mathrm{jam}$.

Kapasitas output dalam 1 bulan (24 HOK) BT Jumbo ini mampu menghasilkan output sebanyak $=48$ proses $\times 760 \mathrm{~kg} / 12 \mathrm{jam}$

$$
=36.480 \mathrm{~kg} / \mathrm{bulan}
$$

Berdasarkan perhitungan diatas, mesin Boll Tea pabrik teh hijau mampu menghasilkan teh kering aktual sebanyak $316.950 \mathrm{~kg} / \mathrm{bulan}$ dengan kapasitas mesin Boll Tea keseluruhan sebesar $100 \%$.

RKAP harian $60.000 \mathrm{~kg}$ pucuk basah (rendemen teh kering 23,5\%), maka akan menghasilkan teh kering sebanyak $14.100 \mathrm{~kg} / \mathrm{hari}$. Dalam 1 bulan (24 HOK) akan menghasilkan rata-rata teh kering sebanyak $338.400 \mathrm{~kg} / \mathrm{bulan}$. Selisih antara kapasitas output BT aktual dengan RKAP bulanan sebesar $21.450 \mathrm{~kg} / \mathrm{bulan}$. Apabila dibagi dengan $24 \mathrm{HOK}$, maka selisih harian sebesar $893,75 \mathrm{~kg} / \mathrm{hari}$. 
Rekomendasi:

Agar pabrik dapat mendekati RKAP, maka perusahaan harus menambah mesin Boll Tea Standar kayu bakar sebanyak 2 unit, dengan perhitungan:

2 unit x $220 \mathrm{~kg} / 12 \mathrm{jam}=440 \mathrm{~kg} / 12$ jam.

Dalam 1 hari, mesin BT ini dapat melakukan 2 kali proses, maka dapat menghasilkan 880 $\mathrm{kg} / \mathrm{hari}$.

Prioritas Alternatif Strategi. Setelah ditemukan beberapa alternatif strategi melalui pendekatan kualitatif dengan matriks TOWS, muncul keterbatasan atas pentingnya setiap faktor dalam pengambilan keputusan karena faktor-faktor tersebut tidak terukur secara kuantitatif. Oleh karena itu, sulit untuk menilai faktor mana saja yang paling mempengaruhi terhadap keputusan strategis. Penggunaan kombinasi dengan Proses Hirarki Analisis (AHP) akan memberikan ukuran kuantitatif atas pentingnya setiap kelompok faktor dan komponennya terhadap proses pengambilan keputusan di dalam pendekatan SWOT tersebut. Menurut Wickramasinghe dan Takano (2009), tujuan dalam memanfaatkan AHP pada kerangka kerja SWOT adalah untuk mengevaluasi secara sistematis faktor SWOT dan menyamakan intensitasnya. Keuntungan melalui penggunaan AHP antara lain pendekatan sistematis untuk masalah keputusan dan dapat diukur dengan standar umum yang dianggap sebagai karakteristik berharga dalam analisis SWOT. Susunan hirarki AHP-SWOT ditampilkan pada Gambar 3.

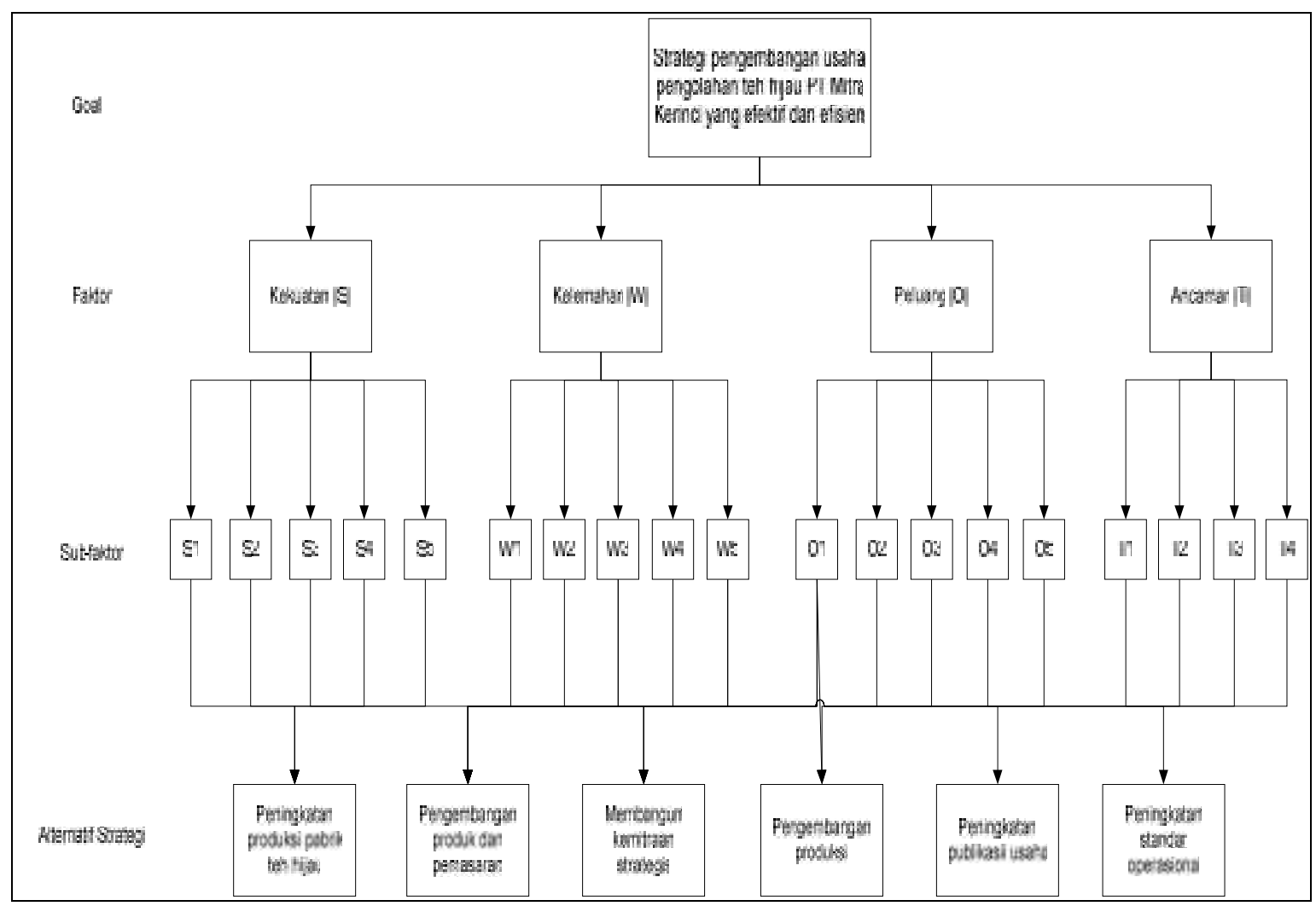

Gambar 3. Struktur Hirarki AHP-SWOT PT XYZ 
Berdasarkan model hirarki di atas, berikut merupakan langkah-langkah yang dilakukan dalam analisis AHP, yaitu sebagai berikut: (1) Level 1 adalah Gol, merupakan tujuan yang ingin dicapai pada penelitian kali ini. (2) Objektif yang menjadi level 2 dari hirarki diperoleh dari faktor-faktor yang diidentifikasi dalam analisis lingkungan internal dan eksternal, yaitu berupa Faktor Kekuatan, Faktor Kelemahan, Faktor Peluang dan Faktor Ancaman. (3) Level 3 merupakan kelompok faktor yang merupakan komponen-komponen dari hasil identifikasi lingkungan internal dan eksternal yaitu berupa kekuatan, kelemahan, peluang dan ancaman yang diurai menjadi $\mathrm{S}_{1}, \mathrm{~S}_{2}, \mathrm{~S}_{\mathrm{n}}, \mathrm{W}_{1}, \mathrm{~W}_{2}, \mathrm{~W}_{\mathrm{n}}, \mathrm{O}_{1}, \mathrm{O}_{2}, \mathrm{O}_{\mathrm{n}}, \mathrm{T}_{1}, \mathrm{~T}_{2}, \mathrm{~T}_{\mathrm{n}}$. (4) Level 4 merupakan alternatif strategi yang dihasilkan dari analisis Matriks TOWS.

Setelah hirarki dari persoalan tersebut disusun, kemudian dilakukan penilaian melalui perbandingan berpasangan (pairwise comparison). Responden akan diberikan kuesioner agar dapat melakukan proses perbandingan berpasangan atas setiap komponen pada level objektif dan kelompok faktor (Level 2 dan Level 3). Responden dapat mengekspresikan pendapat berupa skala Saaty dengan penilaian 1 sampai 9 merupakan yang terbaik (Marimin 2010).

Setelah level faktor dan subfaktor selesai dibobotkan, tahap akhir adalah memberikan nilai efisiensi pada setiap alternatif strategi untuk mengambil keuntungan dari faktor kekuatan, mengurangi efek dari faktor kelemahan, memanfaatkan faktor peluang serta menghadapi faktor ancaman. Menurut Osuna dan Aranda (2007), bagi penilaian efisiensi pada level alternatif strategi (Level 4) menggunakan rumus $V_{j}$ yang didefinisikan sebagai nilai global (relatif) strategi $\mathrm{j}(\mathrm{j}=1,2,3, \ldots \mathrm{n})$. $\mathrm{V}_{\mathrm{j}}$ dapat dirumuskan pada persamaan sebagai berikut:

$$
V_{j}=w_{S} \sum_{i=1}^{i=m L} w_{S i} U_{S i, j}+w_{W} \sum_{i=1}^{i=m w} w_{W i} U_{w_{i, j}}+w_{O} \sum_{i=1}^{i=m e} w_{0 i} U_{O i, j}+w_{T} \sum_{i=1}^{i=m i} w_{T i} U_{T i, j}
$$

Dimana:

$W_{S}, W_{W}, W_{O}, W_{T} \quad=$ Relatif pentingnya setiap kelompok faktor $(\mathrm{S}, \mathrm{W}, \mathrm{O}$ dan $\mathrm{T})$ untuk pencapaian pertumbuhan organisasi dan pengembangan

$W_{S 1 \ldots .} W_{S M S} \quad=$ Relatif pentingnya faktor kekuatan dalam kelompok mereka

$W_{W 1} \ldots W_{W M W}=$ Relatif pentingnya faktor kelemahan dalam kelompok mereka

$W_{1} \ldots W_{\text {OMO }}=$ Relatif pentingnya faktor peluang dalam kelompok mereka

$W_{T 1} \ldots W_{T M T}=$ Relatif pentingnya faktor ancaman dalam kelompok mereka

$U_{S i, j} \quad=$ Efisiensi strategi $j$ dalam mengambil keuntungan dari faktor kekuatan Si $(i=1,2, \ldots, \mathrm{ms})$

$U_{W i, j} \quad=$ Efisiensi strategi $j$ dalam mengurangi efek dari faktor kelemahan $W i(i=1,2, \ldots, \mathrm{mw})$

$U_{O i, j} \quad=$ Efisiensi strategi $j$ dalam memanfaatkan faktor kesempatan Oi $(i=1,2, \ldots$, mo $)$

$U_{T i, j} \quad=$ Efisiensi strategi $j$ dalam menghadapi faktor ancaman $T i(i=1,2, \ldots, \mathrm{mt})$

Dari persamaan tersebut akan diperoleh nilai $\mathrm{V}_{\mathrm{j}}$ dari setiap strategi yang ada. Nilai Efisiensi Strategi $j$ diperoleh dari penilaian efisiensi strategi terhadap setiap komponen faktor menggunakan skala penilaian 0 hingga 5 yang dilakukan oleh responden pakar, dimana urutan peningkatan bobot nilai 0 adalah tidak efisien hingga bobot nilai 5 adalah sangat efisien. Urutan prioritas strategi dapat dilihat pada Tabel 4. 
Darmawan, Daryanto dan Sukardi: Strategi Pengembangan PT XYZ Dalam Agribisnis...

Tabel 4. Urutan Prioritas Strategi Pengolahan Teh Hijau PT XYZ

\begin{tabular}{cclc}
\hline Prioritas & $\begin{array}{c}\text { Tipe } \\
\text { Strategi }\end{array}$ & \multicolumn{1}{c}{ Strategi } & $\begin{array}{c}\text { Nilai Bobot } \\
\text { Global }\end{array}$ \\
\hline 1 & SO & Peningkatan kapasitas produksi pabrik teh hijau & 4,00 \\
2 & WO & Pengembangan kerjasama perusahaan & 3,67 \\
3 & WO & Pengembangan produksi & 3,00 \\
4 & SO & Pengembangan produk dan pemasaran & 2,83 \\
5 & WT & Peningkatan standar operasional & 2,66 \\
6 & ST & Peningkatan publikasi usaha & 1,72 \\
\hline
\end{tabular}

Implikasi Manajerial. Hasil dari prioritas strategi yang menggunakan kombinasi AHP dan SWOT menunjukkan tingkat efisiensi dari setiap strategi untuk mengambil keuntungan dari faktor kekuatan, mengurangi efek dari faktor kelemahan, memanfaatkan faktor peluang dan menghadapi faktor ancaman. Setiap strategi yang dibentuk memiliki kemampuan untuk memenuhi suatu tujuan yang ingin dicapai, dimana dalam proses pelaksanaannya akan dipengaruhi oleh pertimbangan mengenai keterbatasan sumber daya yang dimiliki oleh perusahaan. Hal ini menunjukkan suatu implikasi bahwa keseluruhan alternatif strategi tersebut nantinya dapat dilaksanakan secara bersama-sama atau terpisah. Oleh karena itu, kontribusi dari pemangku kepentingan untuk dapat memperkirakan kapabilitas yang dimiliki serta pengalokasian sumber daya untuk pelaksanaan strategi sangat diperlukan, sehingga pencapaian sasaran utama yaitu strategi pengembangan pengolahan teh hijau PT XYZ yang efektif dan efisien dapat terwujud.

Bentuk implikasi manajerial PT XYZ dapat dilihat pada Tabel 5.

Tabel 5. Implikasi Manajerial PT XYZ

\begin{tabular}{|c|c|c|c|}
\hline $\begin{array}{l}\text { Urutan } \\
\text { Prioritas } \\
\text { (Tahun } \\
\text { Pelaksanaan) }\end{array}$ & $\begin{array}{l}\text { Rekomendasi } \\
\text { Strategi }\end{array}$ & Upaya & Kegiatan \\
\hline $\begin{array}{c}1 . \\
(2013-2014)\end{array}$ & $\begin{array}{l}\text { Peningkatan } \\
\text { kapasitas } \\
\text { produksi } \\
\text { pabrik teh } \\
\text { hijau }\end{array}$ & $\begin{array}{l}\text { Penambahan } \\
\text { jumlah unit } \\
\text { mesin produksi }\end{array}$ & $\begin{array}{l}\text { - Penambahan mesin RP sebanyak } 1 \text { unit. } \\
\text { - Penambahan mesin OTR sebanyak } 2 \text { unit } \\
\text { - Penambahan mesin ECP sebanyak } 5 \text { unit } \\
\text { - Penambahan mesin BT kayu bakar } \\
\text { sebanyak } 2 \text { unit. }\end{array}$ \\
\hline \multirow[t]{3}{*}{$\begin{array}{c}2 . \\
(2013-2014)\end{array}$} & $\begin{array}{l}\text { Pengembang } \\
\text { an kerjasama } \\
\text { perusahaan }\end{array}$ & $\begin{array}{l}\text { Kerjasama } \\
\text { proyek } \\
\text { pembangunan } \\
\text { PLTMH }\end{array}$ & $\begin{array}{l}\text { - Tahap persiapan dengan mengundang } \\
\text { seluruh pemangku kepentingan yang terkait } \\
\text { dalam proyek pembangunan PLTMH, } \\
\text { seperti PLN dan holding, serta melakukan } \\
\text { tender terbuka. }\end{array}$ \\
\hline & & $\begin{array}{l}\text { Kerjasama } \\
\text { produksi ekstrak } \\
\text { teh hijau }\end{array}$ & $\begin{array}{l}\text { - Membina kerjasama teknologi dengan salah } \\
\text { satu perusahaan ekstraksi teh hijau, seperti } \\
\text { PT Indesso Aroma. }\end{array}$ \\
\hline & & $\begin{array}{l}\text { Meningkatkan } \\
\text { kinerja Riset dan } \\
\text { Pengembangan }\end{array}$ & $\begin{array}{l}\text { - Menjalin kerjasama dengan suatu lembaga } \\
\text { atau institusi penelitian terkait dengan } \\
\text { produksi dan produk teh agar dapat }\end{array}$ \\
\hline
\end{tabular}


menciptakan suatu inovasi produksi yang dapat meningkatkan daya saing perusahaan

- Proaktif melakukan kerjasama dengan

Mengembangka sesama anak perusahaan yang bergerak di n kemitraan bidang perdagangan dan distribusi guna dengan sesama anak perusahaan menjajaki peluang pemasaran produk hilir teh hijau

\begin{tabular}{|c|c|c|c|}
\hline \multirow[t]{3}{*}{$\begin{array}{c}3 . \\
(2013-2014)\end{array}$} & \multirow[t]{3}{*}{$\begin{array}{l}\text { Pengembang } \\
\text { an produksi }\end{array}$} & $\begin{array}{l}\text { Penanggulangan } \\
\text { gangguan asap } \\
\text { akibat } \\
\text { pembakaran } \\
\text { kayu }\end{array}$ & $\begin{array}{l}\text { - Quality control teh kering secara berkala, } \\
\text { apabila teridentifikasi smoky maka petugas } \\
\text { langsung memperbaiki kebocoran asap } \\
\text { mesin tsb. } \\
\text { - Menambah diameter cerobong asap tungku } \\
\text { pembakaran. } \\
\text { - Instalasi exhaust fan pada atap pabrik. }\end{array}$ \\
\hline & & $\begin{array}{l}\text { Merekondisi } \\
\text { mesin Boll Tea }\end{array}$ & $\begin{array}{l}\text { - Memperbaiki dan meningkatkan daya } \\
\text { pemanasan mesin Boll Tea yang sudah } \\
\text { memiliki waktu operasional }>15 \text { tahun. } \\
\text { - Modifikasi seluruh mesin Boll Tea kayu } \\
\text { bakar dikonversikan menjadi tenaga listrik. }\end{array}$ \\
\hline & & $\begin{array}{l}\text { Instalasi } \\
\text { conveyor }\end{array}$ & $\begin{array}{l}\text {-Instalasi conveyor antara RP menuju OTR. } \\
\text { - Instalasi conveyor antar ECP Drier. }\end{array}$ \\
\hline \multirow[t]{3}{*}{$\begin{array}{c}4 . \\
(2015-2016)\end{array}$} & \multirow[t]{3}{*}{$\begin{array}{l}\text { Pengembang } \\
\text { an produk } \\
\text { dan } \\
\text { pemasaran }\end{array}$} & $\begin{array}{l}\text { Membuat produk } \\
\text { teh hijau organik } \\
\text { RTD }\end{array}$ & $\begin{array}{l}\text { - Relokasi sisa lahan potensial > } 1.000 \mathrm{~m} \mathrm{dpl} \\
\text { untuk tanaman teh organik. } \\
\text { - Menyiapkan fasilitas produksi teh organik } \\
\text { RTD. } \\
\text { - Menyiapkan tim pengolahan teh organik } \\
\text { RTD. } \\
\text { - Mencari agen retail pemasaran teh organik } \\
\text { RTD. }\end{array}$ \\
\hline & & $\begin{array}{l}\text { Nilai tambah } \\
\text { produk teh } \\
\text { kesehatan }\end{array}$ & $\begin{array}{l}\text { - Membuat produk teh celup kesehatan dalam } \\
\text { kemasan berkualitas premium dengan } \\
\text { blending rempah-rempahan seperti kayu } \\
\text { manis, gambir, kapulaga dan cengkeh. }\end{array}$ \\
\hline & & $\begin{array}{l}\text { Ketepatan waktu } \\
\text { pengiriman }\end{array}$ & $\begin{array}{l}\text { - Menambah jaringan logistik dengan } \\
\text { membuat sistem tender PO diantara 3-4 } \\
\text { rekanan perusahaan logistik. } \\
\text { - Menyiapkan standar prosedur penanganan } \\
\text { complain sebagai bentuk after sales service }\end{array}$ \\
\hline $\begin{array}{c}5 . \\
(2015-2016)\end{array}$ & $\begin{array}{l}\text { Peningkatan } \\
\text { standar } \\
\text { operasional }\end{array}$ & $\begin{array}{l}\text { Mempersiapkan } \\
\text { rancangan } \\
\text { penerapan } \\
\text { standar kerja } \\
\text { GAP }\end{array}$ & $\begin{array}{l}\text { - Clean Soil: melibatkan langkah untuk } \\
\text { mereduksi kemungkinan kontaminasi } \\
\text { microbial pada tanah, terutama melalui } \\
\text { kotoran hewan lain dan manajemen pupuk } \\
\text { - Clean Water: memastikan semua air yang }\end{array}$ \\
\hline
\end{tabular}


digunakan dalam proses irigasi dan sarana produksi adalah kualitas air minum

(UKDA 2012) menerapkan kebersihan pribadi yang baik di lapangan \& pabrik

- Clean Surfaces: memastikan semua pengepakan, permukaan kerja, tempat penyimpanan dan kendaraan transportasi dicuci dengan benar dan disterilkan secara teratur

-Proaktif mengundang dan berkonsultasi bersama pakar SNI untuk mengetahui aturan yang harus dipenuhi dalam rangka legalitas sertifikasi SNI

Mempersiapkan

- Melakukan audit dengan membandingkan persyaratan sertifikasi SNI antara persyaratan SNI dengan kondisi eksisting di lapangan

- Membenahi kelengkapan peralatan agar sesuai dengan persyaratan

- Menata layout pabrik yang disesuaikan dengan penambahan jumlah mesin produksi baru.

Peremajaan pabrik teh hijau

- Memperluas pabrik teh hijau sehingga WT dan RP mendapatkan ruang tertutup di dalam pabrik.

\begin{tabular}{cll}
\hline 6. & Peningkatan & Mengadakan \\
$(2015-2016)$ & publikasi & Gerakan Lestari \\
& usaha & Teh Indonesia
\end{tabular}

- Proaktif mengajak Perkebunan Pemerintah, Swasta dan Rakyat membuat event akbar bertemakan lestari teh dalam negeri yang diakomodir oleh pemerintah, Dewan Teh Indonesia dan Asosiasi Teh Indonesia.

Mengadakan kompetisi kuliner

-Mengadakan festival kuliner bertemakan penggunaan teh hijau pada kuliner.

\section{PENUTUP}

Simpulan. Faktor-faktor internal dan eksternal yang mempengaruhi pengembangan usaha pengolahan teh hijau pada PT XYZ adalah: (1) Faktor-faktor internal yang dimiliki oleh PT XYZ terdiri dari kekuatan dan kelemahan. Adapun, kekuatan yang dimiliki perusahaan adalah kondisi finansial kuat karena didukung oleh pihak holding, produsen teh hijau terbesar di Indonesia, aset kebun HGU luas dan menunjang sebagai kebun teh, umur tanaman teh produktif dengan kandungan kadar tanin tergolong tinggi dan akses mudah mengikuti pameran sebagai delegasi negara. Sedangkan, kelemahan yang dimiliki 
perusahaan adalah beban biaya energi cukup besar, gangguan asap pembakaran kayu, waktu proses Pengeringan II masih terlalu lama, jumlah antrian pucuk di WT masih cukup banyak, pemberdayaan Riset dan Pengembangan belum optimal.; (2) Faktor-faktor eksternal yang mempengaruhi pengembangan usaha pengolahan teh hijau terdiri dari peluang dan ancaman. Peluang tersebut antara lain: kebutuhan teh industri manufaktur terus meningkat, jumlah penduduk Indonesia ke-4 terbesar di dunia, penduduk kelas menengah Indonesia terus meningkat, minat teh organik masyarakat dunia terus meningkat dan peluang bisnis teknologi ektraksi teh hijau. Ancaman yang perlu diperhatikan oleh PT XYZ, antara lain impor teh Indonesia terus meningkat, program GPATN rehabilitasi kebun teh rakyat, rendahnya apresiasi masyarakat Indonesia terhadap teh berkualitas dan penerapan SNI wajib untuk teh. (3) Berdasarkan analisis rantai nilai, analisis lingkungan internal dan analisis lingkungan eksternal, maka dirumuskan beberapa alternatif strategi yang dapat dilakukan oleh PT XYZ, yaitu: strategi SO terdiri dari peningkatan kapasitas produksi pabrik teh hijau dan pengembangan produk dan pemasaran, strategi WO terdiri dari pengembangan kerjasama perusahaan dan pengembangan produksi, strategi ST terdiri atas peningkatan publikasi usaha dan strategi WT terdiri atas peningkatan standar operasional.

Analisis lanjutan untuk menentukan prioritas strategi didapatkan dari urutan besaran nilai bobot global melalui teknik analisis AHP-SWOT. Adapun prioritas strategi yang dihasilkan berturut-turut adalah: (1) peningkatan kapasitas produksi pabrik teh hijau; (2) pengembangan kerjasama perusahaan; (3) pengembangan produksi; (4) pengembangan produk dan pemasaran; (5) peningkatan standar operasional; (6) peningkatan publikasi usaha.

Saran. (1) Bagi penelitian selanjutnya dapat lebih ditekankan pada strategi pengembangan pemasaran teh PT XYZ dengan lebih mendalami wawancara kepada trader, blender serta industri manufaktur. (2) Bagi perusahaan. sebaiknya segera menambah tim Riset dan Pengembangan serta mengembangkan deskripsi kerja penelitian yang tidak hanya terfokus pada pengembangan produk turunan teh saja, melainkan juga dapat mengembangkan inovasi produksi baik di tingkat kebun maupun tingkat pabrik sehingga mampu meningkatkan efisiensi serta daya saing perusahaan.

\section{DAFTAR RUJUKAN}

Adam J. (2005) Analyze your company using SWOTs. Supply House Times: 48(7):26-28.

[BPS] Badan Pusat Statistik. (2011) Statistik Teh Indonesia [Internet]. [diunduh 2014 Jan 25]. Tersedia pada: http://www.bps.go.id/hasil_publikasi/stat_teh_2011/index3.php?pub=Statistik\%20T eh\%20Indonesia\%202011

David F.,R., (2007) Strategic Management, Concept and Cases. New Jersey (US): Prentice Hall.

Marimin, Maghfiroh N. (2010) Aplikasi Teknik Pengambilan Keputusan dalam Manajemen Rantai Pasok. Bogor (ID): PT Penerbit IPB Press.

Moser HC. (2006) How to SWOT Southeast Asia. Manufacturing Engineering. 136(1):120.

Pietrobelli C, Rabelloti R. (2005) Upgrading of Global Value Chain: Lessons from Latin American Clusters. Great Britain (UK): Elsevier Ltd. 
Osuna EE, Aranda A. (2007) Combining SWOT and AHP techniques for strategic planning. ISAHP; Viña del Mar, Chile, August 2-6, 2007.

[UKDA] University of Kenctucy Department of Agriculture. (2012) Good Agricultural Practices (GAP) [Internet]. [diunduh pada 2014 Juli 12]. Tersedia pada: http://www.uky.edu/Ag/CDBREC/introsheets/gap.pdf

Umar H. (2003) Strategic Management in Action: Konsep, Teori Dan Teknik Menganalisis Manajemen Strategis Business Unit Berdasarkan Konsep Michael R. Porter, Fred R. David dan Wheelen-Hunger. Jakarta: Gramedia Pustaka Utama.

Wickramasinghe V, Takano S. (2009) "Application of Combined SWOT and Analytic Hierarchy Process (AHP) for Tourism Revival Strategic Marketing Planning: A Case of Sri Lanka Tourism". Journal of the Eastern Asia Society for Transportation Studies. 8 (nomor dan halaman tidak tercantum).

Widiarsono A. (2010) Strategic value chain analysis (Analisis Stratejik Rantai Nilai): Suatu Pendekatan Manajemen Biaya. Program Studi Akuntansi Fakultas Pendidikan Ekonomi dan Bisnis. Universitas Pendidikan Indonesia (UPI BHMN) Bandung [internet]. [cited in $2014 \mathrm{Feb} 18$ ]. Available from http://agusw77.wordpress.com 